\title{
Diagnosis of asbestosis by a time expanded wave form analysis, auscultation and high resolution computed tomography: a comparative study
}

\author{
Nabil Al Jarad, B Strickland, G Bothamley, S Lock, R Logan-Sinclair, R M Rudd
}

\begin{abstract}
Background-Crackles are a prominent clinical feature of asbestosis and may be an early sign of the condition. Auscultation, however, is subjective and interexaminer disagreement is a problem. Computerised lung sound analysis can visualise, store, and analyse lung sounds and disagreement on the presence of crackles is minimal. High resolution computed tomography (HRCT) is superior to chest radiography in detecting early signs of asbestosis. The aim of this study was to compare clinical auscultation, time expanded wave form analysis (TEW), chest radiography, and HRCT in detecting signs of asbestosis in asbestos workers.
\end{abstract}

Methods-Fifty three asbestos workers (51 men and two women) were investigated. Chest radiography and HRCT were assessed by two independent readers for detection of interstitial opacities. HRCT was performed in the supine position with additional sections at the bases in the prone position. Auscultation for persistent fine inspiratory crackles was performed by two independent examiners unacquainted with the diagnosis. TEW analysis was obtained from a 33 second recording of lung sounds over the lung bases. TEW and auscultation were performed in a control group of 13 subjects who had a normal chest radiograph. There were 10 current smokers and three previous smokers. In asbestos workers the extent of pulmonary opacities on the chest radiograph was scored according to the International Labour Office (ILO) scale. Patients were divided into two groups: 21 patients in whom the chest radiograph was $>1 / 0$ (group 1 ) and 32 patients in whom the chest radiograph was scored $\leqslant 1 / 0$ (group 2 ) on the ILO scale.

Results-In patients with an ILO score of $\leqslant 1 / 0$ repetitive mid to late inspiratory crackles were detected by auscultation in seven $(22 \%)$ patients and by TEW in 14 (44\%). HRCT detected definite interstitial opacities in 11 (34\%) and gravity dependent subpleural lines in two $(6 \%)$ patients. All but two patients with evidence of interstitial disease or gravity dependent subpleural lines on HRCT had crackles detected by TEW. In patients with an ILO score of $>1 / 0$ auscultation and TEW revealed mid to late inspiratory crackles in all patients, whereas HRCT revealed gravity dependent subpleural lines in one patient and signs of definite interstitial fibrosis in the rest. In normal subjects crackles different from those detected in asbestosis were detected by TEW in three subjects but only in one subject by auscultation. These were early, fine inspiratory crackles.

Conclusion-Mid to late inspiratory crackles in asbestos workers are detected by TEW more frequently than by auscultation. Signs of early asbestosis not apparent on the plain radiograph are detected by TEW and HRCT with similar frequency.

\section{(Thorax 1993;48:347-353)}

Early stages of asbestosis usually escape recognition. ${ }^{1}$ Symptomatology is subjective and radiographic manifestations of early stages of interstitial lung disease are difficult to distinguish from normal shadows. ${ }^{23} \mathrm{High}$ resolution computed tomography (HRCT) is more sensitive than plain radiography in detecting early asbestosis. ${ }^{34}$ Crackles have been recognised as a prominent feature of pulmonary asbestosis ${ }^{5}$ and are thought to be an early finding. ${ }^{67}$ Auscultation, however, is highly subjective and observer variability is a problem. ${ }^{8}$ The development of systems which allow visualisation of lung sounds and production of time expanded displays has increased the potential value of lung sound analysis. ${ }^{9}$ Crackles in asbestos workers with no radiographic evidence of asbestosis were detected by auscultation in $19 \%$ in one study ${ }^{7}$ and in $32 \%$ in another. ${ }^{10}$ Using time expanded wave form analysis (TEW) crackles were detected in $22 \%$ of asbestos workers with no chest radiographic evidence of asbestosis. ${ }^{11}$

In this study the values of clinical examination, HRCT, and TEW analysis in detecting signs of asbestosis are compared in 53 asbestos workers.

\section{Methods}

PATIENTS

Fifty three asbestos workers who presented for assessement of the possibility of asbestos 


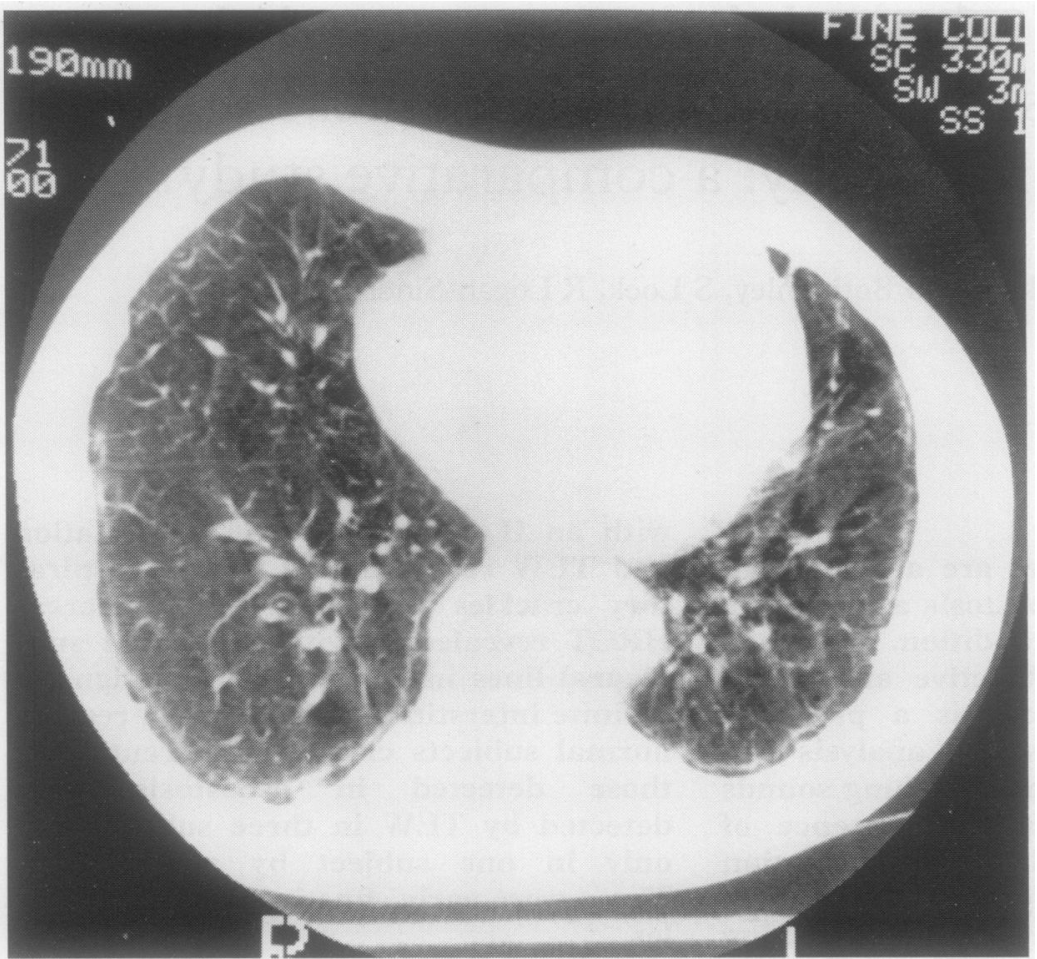

Figure 1 Asbestosis. Thin, bilateral, well defined posterior subpleural lines are visible which start from the paravertebral area and extend to the anterior aspect for the left lung and lateral aspect of the right lung.

related disease were studied. There were two women and 51 men. The mean duration of asbestos exposure was $11 \cdot 3$ (range 1-35) years. Thirty four had worked in the lagging industry, 17 had carried out asbestos cutting, milling and spinning, and the two women had been exposed to asbestos through cleaning clothes contaminated with asbestos for more than 20 years. There were 18 smokers (smoked within the last three months), 28 ex-

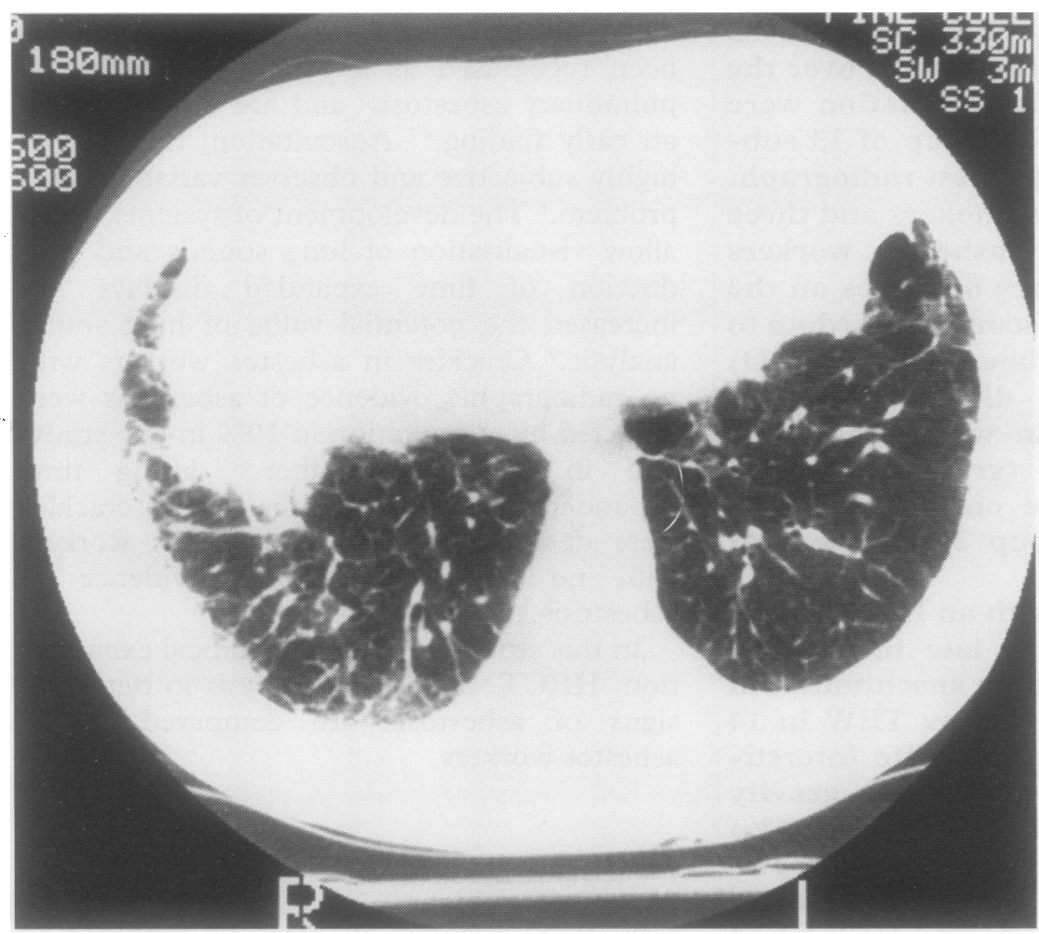

Figure 2 Asbestosis. Coarse reticulonodular opacities can be seen on both lung fields which merge with a thickened posterior and diaphragmatic pleura. smokers (smoked more than one cigarette daily for more than 20 years but no cigarettes during the last three months), and seven nonsmokers (smoked less than one cigarette a day for less than 20 years and no cigarettes during the last three months). None of the patients had any symptoms, chest radiographic or electrocardiographic evidence of heart disease.

Thirteen control subjects (four women and nine men) of mean age 49 (range 33-64) years were investigated. There were 10 current smokers and three previous smokers. They all had a normal chest radiograph. None of them had any previous exposure to asbestos and none had current or past history of respiratory or cardiac problems.

\section{ASSESSMENT OF THE CHEST RADIOGRAPHS}

For the purpose of this study profusion of small parenchymal opacities in both lung fields was assessed independently by two readers on a 12 point scale according to the International Labour Office (ILO) method. ${ }^{12}$ The two readers were experienced in the use of the ILO system. The average score of both readers was then taken. Patients were divided into two groups: group 1 consisted of 21 patients with definitive radiological evidence of asbestosis (chest radiographic score of $>1 / 0$ on the ILO scale) and group 2 comprised 32 patients without definitive evidence of asbestosis (chest radiograph score of $\leqslant 1 / 0$ on the ILO scale).

\section{HRCT METHODOLOGY}

HRCT scans were carried out in asbestos workers as part of their clinical assessment (but not in normal subjects). The scans were performed with an Elscint 2002 or Phillips Tomoscan CX scanners with a scanning time of 5.5 seconds. $3 \mathrm{~mm}$ sections $10 \mathrm{~mm}$ apart were obtained from lung apices to bases in full inspiration up to total lung capacity. The mean CT window was 1600 (range 1460-1803) Hounsfield units. Additional sections were repeated in the prone position to identify whether opacities seen in the posterior aspects of the lungs in the supine positions persisted or disappeared on the prone sections. ${ }^{1314}$ Asbestosis was considered to be present if one or more of the following types of opacities were present: (a) subpleural curvilinear line (fig 1); (b) coarse linear and reticular opacities which merge with the pleura (fig 2); and (c) confluent (ground glass) opacities (fig 3). ${ }^{15}$

\section{CLINICAL EXAMINATION}

Auscultation over the posterior aspect of the lung fields was performed by two independent examiners unaware of the diagnosis or the purpose of the study. Examiners were asked to comment on the presence, timing, and nature of any persistent adventitious lung sounds (crackles, wheeze, or any other abnormal lung sound). Clinical examination was considered positive when two examiners agreed that there were repetitive fine late or mid to late inspiratory crackles. 


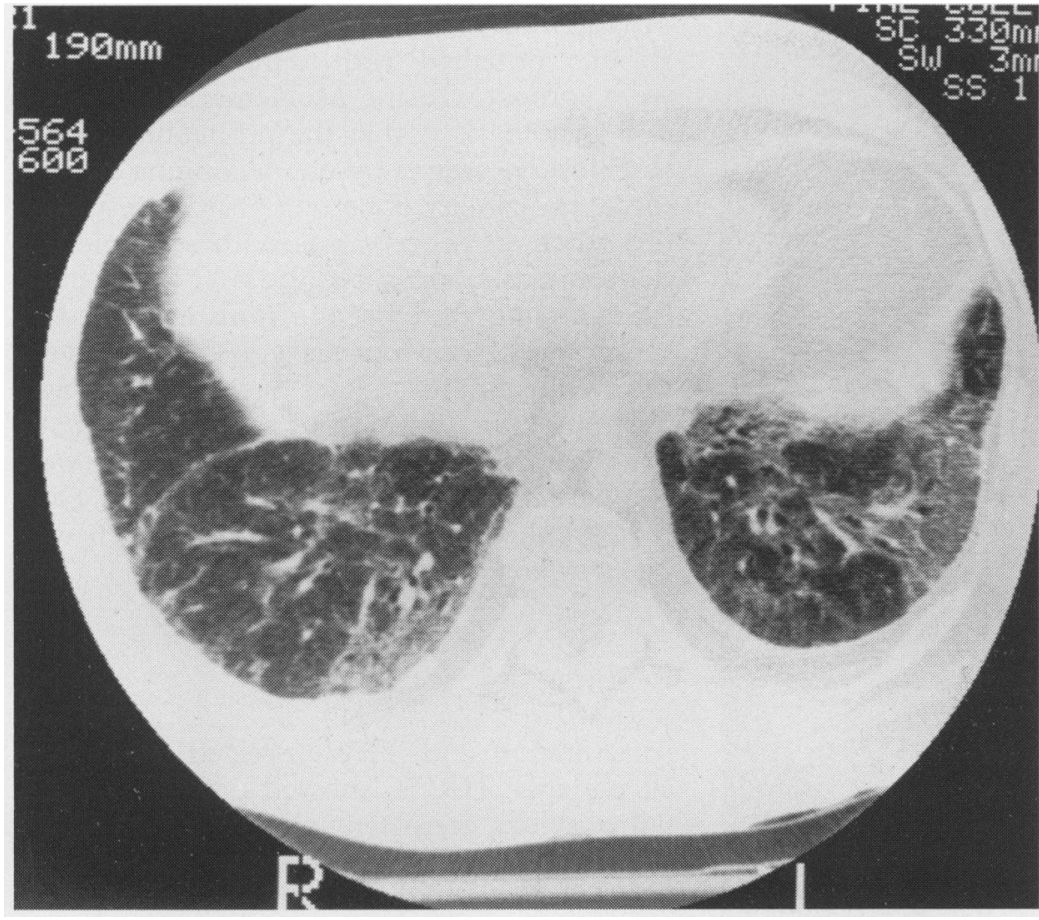

Figure 3 Asbestosis. Confluent (alveolar, ground glass) and reticulonodular opacities are visible in both lung fields.

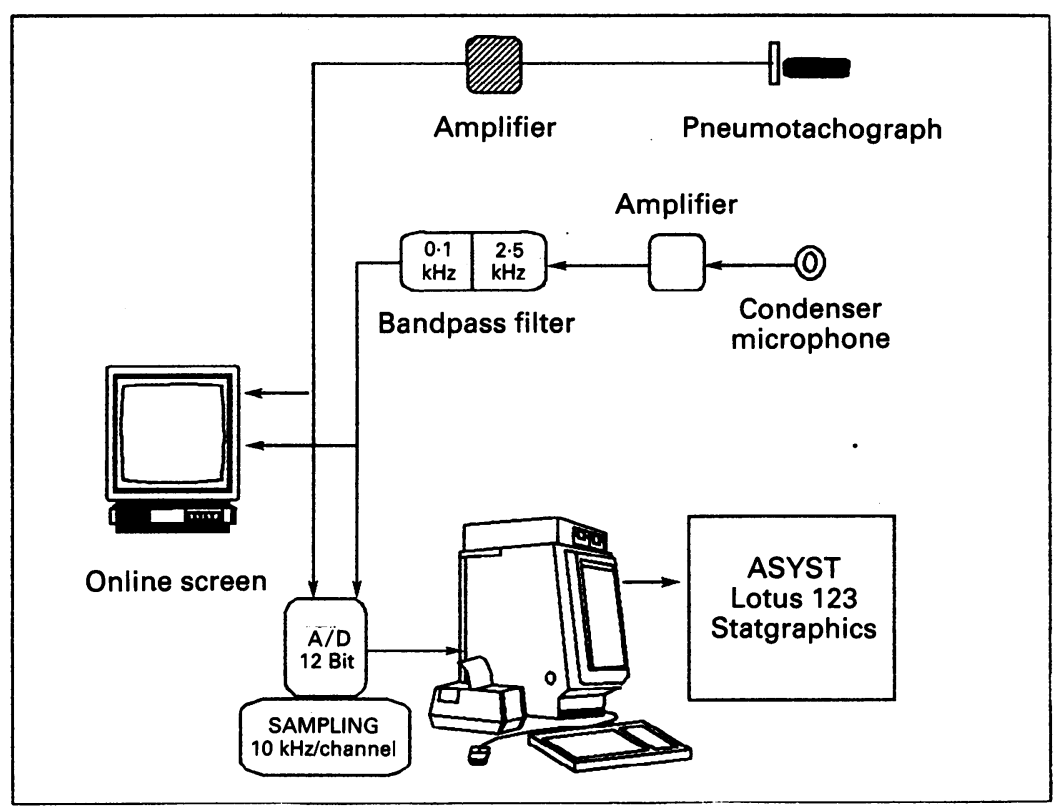

Figure 4 Lung sound system.

\section{SOUND RECORDING \\ Lung sound system (fig 4)}

The lung sound system consisted of a Knowles type BL-1670 ceramic microphone which incorporates its own field effect transistor buffer stage. This microphone can be

Table 1 Mean (SD) demographic data of asbestos workers with a chest radiographic score of $\leqslant 1 / 0$.

\begin{tabular}{lllll}
\hline & $\begin{array}{l}0 / 0 \\
(n=17)\end{array}$ & $\begin{array}{l}0 / 1 \\
(n=4)\end{array}$ & $\begin{array}{l}1 / 0 \\
(n=11)\end{array}$ & pvalue $^{*}$ \\
\hline Age & $57.5(10.9)$ & $54 \cdot 8(9 \cdot 8)$ & $57.5(10.9)$ & NS \\
$\begin{array}{l}\text { Smoking(pack years) } \\
\begin{array}{c}\text { Duration of asbestos } \\
\quad \text { exposure(years) }\end{array}\end{array}$ & $18.2(21 \cdot 6)$ & $29.7(15 \cdot 6)$ & $18.2(21 \cdot 6)$ & NS \\
$\begin{array}{l}\text { Time since first } \\
\text { asbestos exposure(years) }\end{array}$ & $11.5(7 \cdot 8)$ & $10.3(8 \cdot 8)$ & $11.5(7 \cdot 8)$ & NS \\
\hline
\end{tabular}

^One way analysis of variance. attached to the chest wall by double sided adhesive tape. The frequency response of the microphone is flat to within $3 \mathrm{~dB}$ between $200 \mathrm{~Hz}$ and $5 \mathrm{kHz}$. The audio signal is subjected to initial amplification via an amplifier with a gain of 10 . The sound signal is then filtered with an electronic filter EF5 (Fern Developments, formerly Barr at Stroud Ltd). These filters can be set digitally to behave as a bandpass filter with a low and a high pass roll at $48 \mathrm{~dB}$ /octave. The low pass filter $3 \mathrm{~dB}$ point was fixed at $2.5 \mathrm{kHz}$ and the high pass filter $3 \mathrm{~dB}$ point was set at $100 \mathrm{~Hz}$ to cut out the low frequency sounds, particularly heart sounds. The sound signal can be seen on a real time display and is sent to a multichannel data acquisition board (type DT 2821) installed in an IBM compatible PC AT (Tandon). This board consists of a multichannel analog to digital (A/D) converter. The sampling rate of each channel of the $A / D$ converter is set at $10 \mathrm{kHz}$.

Flow at the mouth was recorded with a pneumotachograph and low pressure transducer (type EMT 32c). The signal was further conditioned via an instrumentation amplifier and its output fed both to the real time display and to the $A / D$ converter. The flow signal and the sound signal can be superimposed for identification of the timing of events.

The software was developed using the scientific programming language "ASYST". The recording time was 33 seconds. For TEW analysis a compressed display of $2 \cdot 7$ seconds can be produced by combining a number of subfiles, and more detailed analysis can be performed on window of a $100 \mathrm{~ms}$. The cost of the equipment was about $£ 5000$ (1988-9 prices).

Sound recording and clinical examination were performed within one hour. The microphone was moved over both lung fields posteriorly before the recording and the on line screen was observed. The recordings were performed while the microphone was attached to the area where signals suggesting lung crackles were observed on the screen.

A crackle was considered to be present when a sound complex met the following criteria: ${ }^{16}$ (a) the amplitude of the largest peak was greater than double that of the background sound; (b) the beginning of the event had a sharp negative or positive deflection; (c) crossing of the base line by deflections was progressively wider. For the purpose of comparison with auscultation, crackles were considered present on the TEW analysis when at least six complexes were identified in three successive cycles (two complexes per cycle).

A fine crackle was considered to be present when the initial deflection width (IDW) and the two cycle duration (2CD) were $<0.92 \mathrm{~ms}$ and $<6.05 \mathrm{~ms}$ respectively. ${ }^{17}$

\section{VITAL CAPACITY}

Vital capacity was measured with a dry cylinder spirometer (PK Morgan, UK) and expressed as a percentage of the predicted value for age, sex, and height. ${ }^{18}$ 

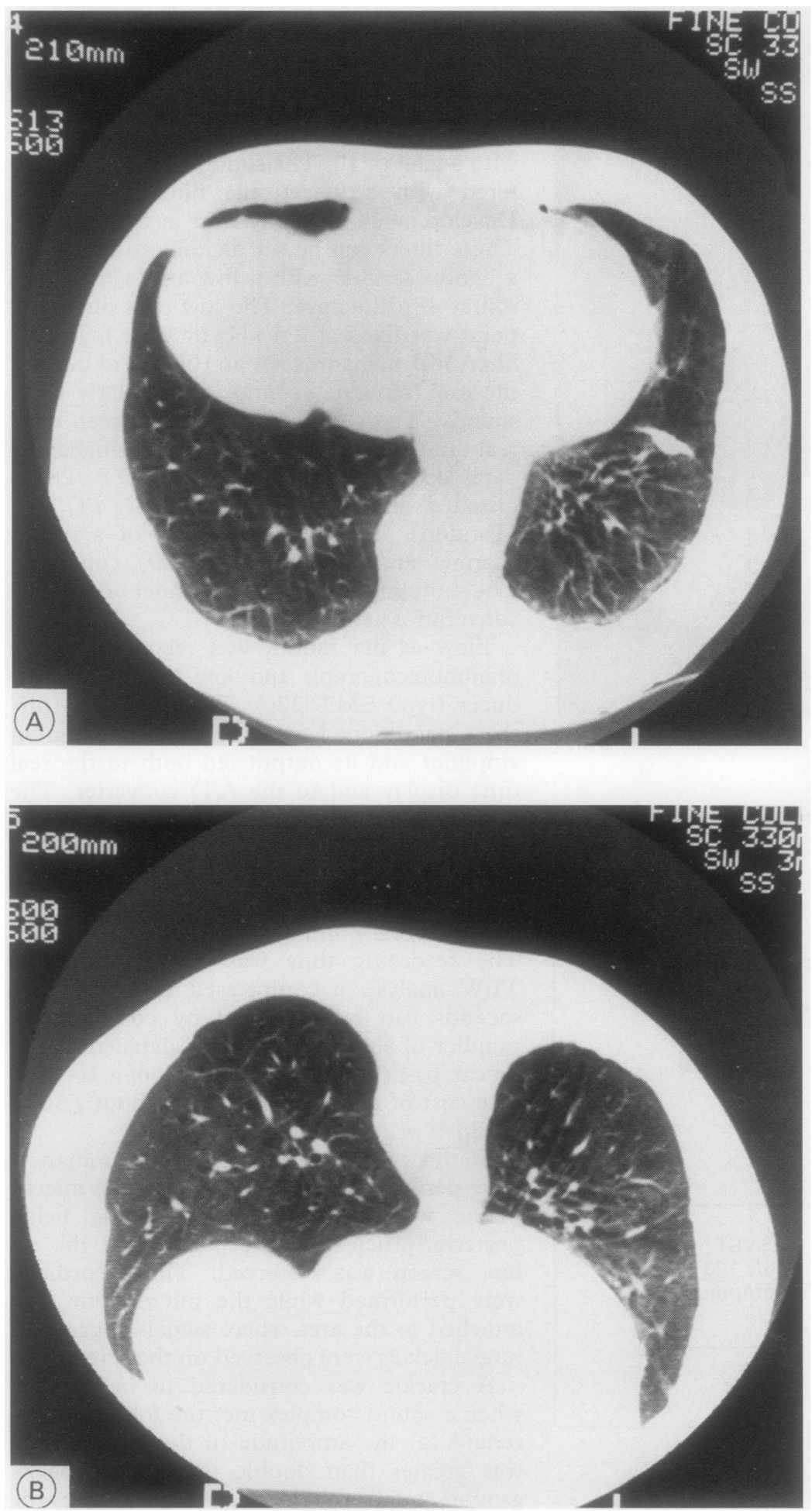

Figure 5 (A) Linear shadows in the posterior subpleural areas in a 58 year old previous lagger (patient no. 24). (B) $A$ section taken of the same area in the prone position shows that the lines have disappeared.

\section{STATISTICAL ANALYSIS}

Results obtained with different techniques were compared using McNemar's test. ${ }^{19}$ The null hypothesis is that the probability of getting positive results by one technique is equal to the probability of getting positive results by the other. In other words both tests pick up the same number of positives. The formulae for analysing paired proportions are based on those pairs showing disagreement between the two techniques. Age, pack years of cigarette smoking, duration of asbestos exposure, and time since first asbestos exposure were compared in patients in whom the chest radiograph score was $0 / 0,0 / 1$, and $1 / 0$ with one way analysis of variance.

\section{Results}

GROUP 1

Auscultation and TEW revealed crackles in all patients. HRCT showed definite interstitial opacities consistent with asbestosis in all but one patient in whom discrete subpleural lines in the posterior basal lung fields in the supine but not the prone position sections were seen (gravity dependent subpleural lines). In this patient crackles were detected by the two examiners and by TEW. The HRCT sections and the TEW display of this patient are illustrated in figs 5 and 6 .

GROUP 2

Table 1 shows demographic data for patients in whom the chest radiograph score was $0 / 0$, $0 / 1$, and $1 / 0$. There were no differences between groups in age, duration of asbestos exposure, and time since first asbestos exposure.

Tables 2,3 , and 4 show the results in patients in whom signs of asbestosis were detected by various techniques. Crackles (the term crackles will be used in the rest of the text to describe fine mid to late inspiratory crackles) were detected by TEW (fig 7) more frequently than by auscultation $(p<0.04)$ (table 3). HRCT detected gravity dependent discrete subpleural lines in two (6\%) patients; auscultation and TEW detected crackles in both. In some patients in whom the chest radiograph did not show evidence of asbestosis (ILO score of $0 / 0$ and $0 / 1$ ) crackles were still detected by TEW and to a lesser extent by auscultation, and pulmonary opacities were detected by HRCT (table 4).

In patients in whom the vital capacity was $\geqslant 80 \%$ of predicted value $(n=21)$ crackles were detected by auscultation in four (19\%) and by TEW in eight (38\%); HRCT showed interstitial fibrosis in six $(29 \%)$ and gravity dependent subpleural lines in two (10\%).

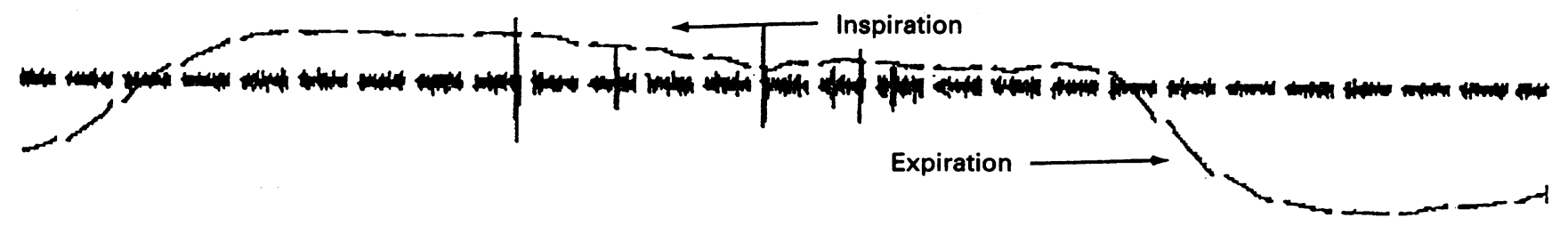


Table 2 Results of chest radiography, high resolution computed tomography (HRCT), auscultation, and time expanded waveform analysis (TEW) in group 2 (patients in whom the chest radiograph score was $\leqslant 1 / 0$ ).

\begin{tabular}{|c|c|c|c|c|c|}
\hline No & $\begin{array}{l}\text { ILO score for } \\
\text { chest radiography }\end{array}$ & $H R C T$ & Auscultation & $T E W$ & $\begin{array}{l}F V C \\
\text { (\% predicted) }\end{array}$ \\
\hline 1 & $0 / 0$ & + & - & + & 121 \\
\hline 2 & $0 / 0$ & - & - & + & 74 \\
\hline 3 & $0 / 0$ & - & - & - & 92 \\
\hline 4 & $0 / 0$ & - & - & - & 81 \\
\hline 5 & $0 / 0$ & - & - & - & 125 \\
\hline 6 & $0 / 0$ & - & - & - & 89 \\
\hline 7 & $0 / 0$ & - & - & - & 113 \\
\hline 8 & $0 / 0$ & - & - & - & 106 \\
\hline 9 & $0 / 0$ & - & - & - & 113 \\
\hline 10 & $0 / 0$ & - & - & - & 96 \\
\hline 11 & $0 / 0$ & - & - & - & 94 \\
\hline 12 & $0 / 0$ & - & - & - & 79 \\
\hline 13 & $0 / 0$ & - & - & - & 73 \\
\hline 14 & $0 / 0$ & - & - & - & 80 \\
\hline 15 & $0 / 0$ & - & - & - & 75 \\
\hline 16 & $0 / 0$ & - & - & + & 88 \\
\hline 17 & $0 / 0$ & - & - & - & 89 \\
\hline 18 & $0 / 1$ & $-*$ & + & + & 97 \\
\hline 19 & $0 / 1$ & + & - & + & 83 \\
\hline 20 & $0 / 1$ & - & - & + & 70 \\
\hline 21 & $0 / 1$ & + & + & + & 71 \\
\hline 22 & $1 / 0$ & - & - & - & 81 \\
\hline 23 & $1 / 0$ & + & + & + & 99 \\
\hline 24 & $1 / 0$ & $-\star *$ & + & + & 92 \\
\hline 25 & $1 / 0$ & + & - & - & 87 \\
\hline 26 & $1 / 0$ & + & + & + & 75 \\
\hline 27 & $1 / 0$ & + & + & + & 72 \\
\hline 28 & $1 / 0$ & + & - & + & 69 \\
\hline 29 & $1 / 0$ & + & - & - & 50 \\
\hline 30 & $1 / 0$ & + & + & + & 85 \\
\hline 31 & $1 / 0$ & + & - & + & 83 \\
\hline 32 & $1 / 0$ & - & - & - & 49 \\
\hline
\end{tabular}

^In those patients gravity-dependent subpleural lines were detected on HRCT. FVC-forced vital capacity.

Table 3 Number of patients with chest radiograph score of $\leqslant 110$ in whom signs of asbestosis (fine mid to late inspiratory crackles by auscultation and TEW and pulmonary fibrosis on HRCT) were detected by one technique but not another, by both techniques or by neither of them.

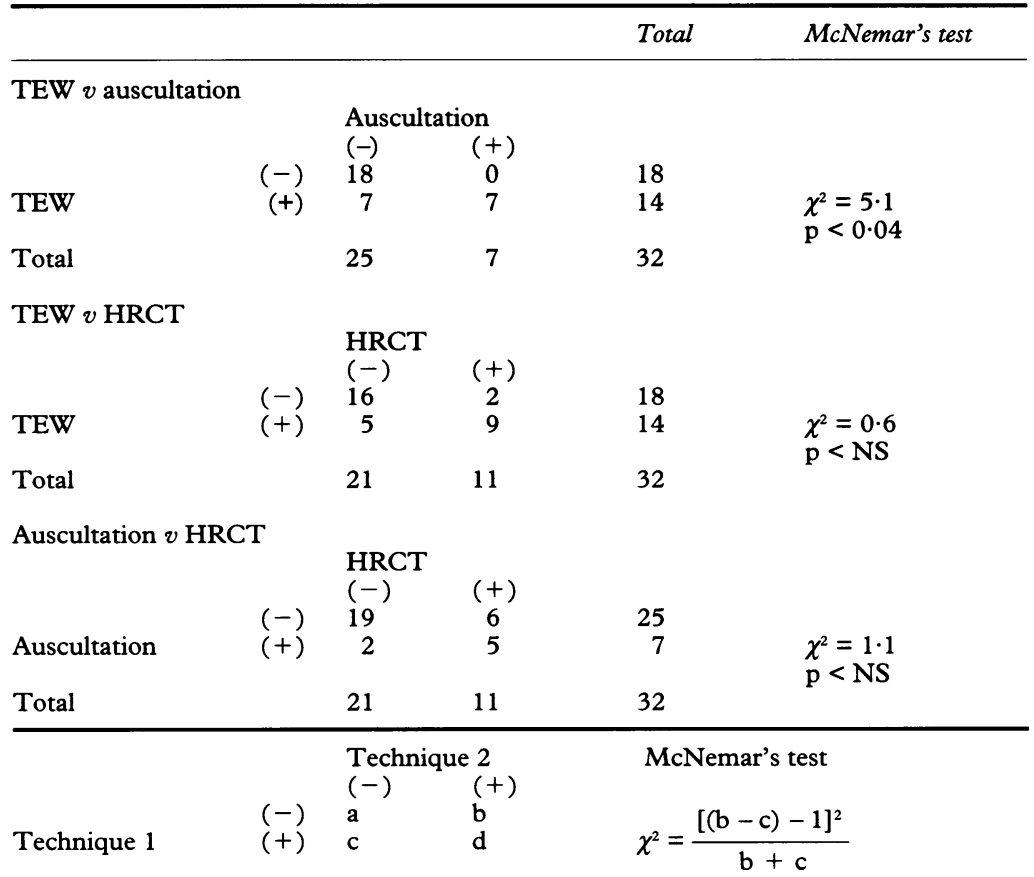

Table 4 Frequency of detecting crackles by auscultation and TEW and pulmonary opacities by HRCT in patients with various degrees of pulmonary opacities on the ILO scale.

\begin{tabular}{lllll}
\hline & $\begin{array}{l}0 / 0 \\
(n=17)\end{array}$ & $\begin{array}{l}0 / 1 \\
(n=4)\end{array}$ & $\begin{array}{l}1 / 0 \\
(n=11)\end{array}$ & $\begin{array}{l}0 / 0+0 / 1+1 / 0 \\
(n=32)\end{array}$ \\
\hline Crackles by auscultation & $0(0 \%)$ & $2(50 \%)$ & $5(45 \%)$ & $7(22 \%)$ \\
Crackles by TEW & $3(18 \%)$ & $4(100 \%)$ & $7(64 \%)$ & $14(44 \%)$ \\
Pulmonary opacities on HRCT & $1(6 \%)$ & $2(50 \%)$ & $8(73 \%)$ & $11(34 \%)$ \\
\hline
\end{tabular}

NORMAL SUBJECTS

Crackles were detected by TEW in three of the 13 subjects. They presented as fine early inspiratory crackles (fig 8) and were detected in only one subject by auscultation.

\section{Discussion}

In patients without definite evidence of asbestosis on chest radiography (ILO score of $\leqslant 1 / 0$ ) both HRCT and TEW were superior to auscultation in detecting signs of asbestosis. Staples $e t a^{3}$ reported definite evidence of asbestosis on HRCT in $34 \%$ of 169 patients in whom the chest radiograph was normal or near normal (ILO score $<1 / 0$ ). In the present study definite evidence of asbestosis on HRCT in a similar group of 21 patients was found in only $14 \%$ but the $95 \%$ confidence interval (3-36\%) included the proportion reported by Staples et al. ${ }^{3}$ The HRCT opacities were not entirely specific for asbestosis. We have previously shown that there is an overlap between HRCT features of asbestosis and cryptogenic fibrosing alveolitis. ${ }^{15}$

TEW detected crackles in all but two patients in whom asbestosis was diagnosed by HRCT and in three patients in whom HRCT showed no abnormality. These techniques can therefore detect asbestosis not apparent on plain radiographs with a similar frequency.

There is an uncertainty as to the significance of gravity dependent subpleural opacities on HRCT. Crackles were detected by TEW and by auscultation in the three patients in whom these opacities disappeared in the prone position. This suggests that these appearances may be signs of early interstitial fibrosis highlighted by the gravity induced blood diversion.

In 270 asbestos factory workers Shirai et $a l^{10}$ reported that the frequency of crackles as detected by auscultation was $32 \cdot 2 \%$. This figure was higher than those reported by Kleinfield et $a l^{7}$ and Wallace and coworkers ${ }^{20}$ who found crackles in $19.6 \%$ and $18 \%$ of asbestos workers respectively. Murphy et $a l^{11}$ showed that two trained technicians reported crackles in $22 \%$ of 289 asbestos workers in whom neither functional (vital capacity $>80 \%$ ) nor radiographic evidence of asbestosis was present. The criteria for definitive radiographic evidence of asbestosis, however, were more stringent and required a score of $1 / 2$ or more on the ILO scale. In the present study crackles were detected by auscultation in $19 \%$ and by TEW in $38 \%$ of cases in patients in whom the chest radiograph score was $\leqslant 1 / 0$ and vital capacity measurement was $\geqslant 80 \%$ of predicted. In this group HRCT detected definite evidence of asbestosis or gravity dependent subpleural lines in $38 \%$ of cases.

Murphy et $a l^{11}$ believed that crackles which were detected in the $22 \%$ of patients with no functional or radiological signs of asbestosis may have been evidence of early stages of asbestosis and others have suggested that crackles may be the earliest sign of asbestosis. ${ }^{51021}$ Microscopic changes of 


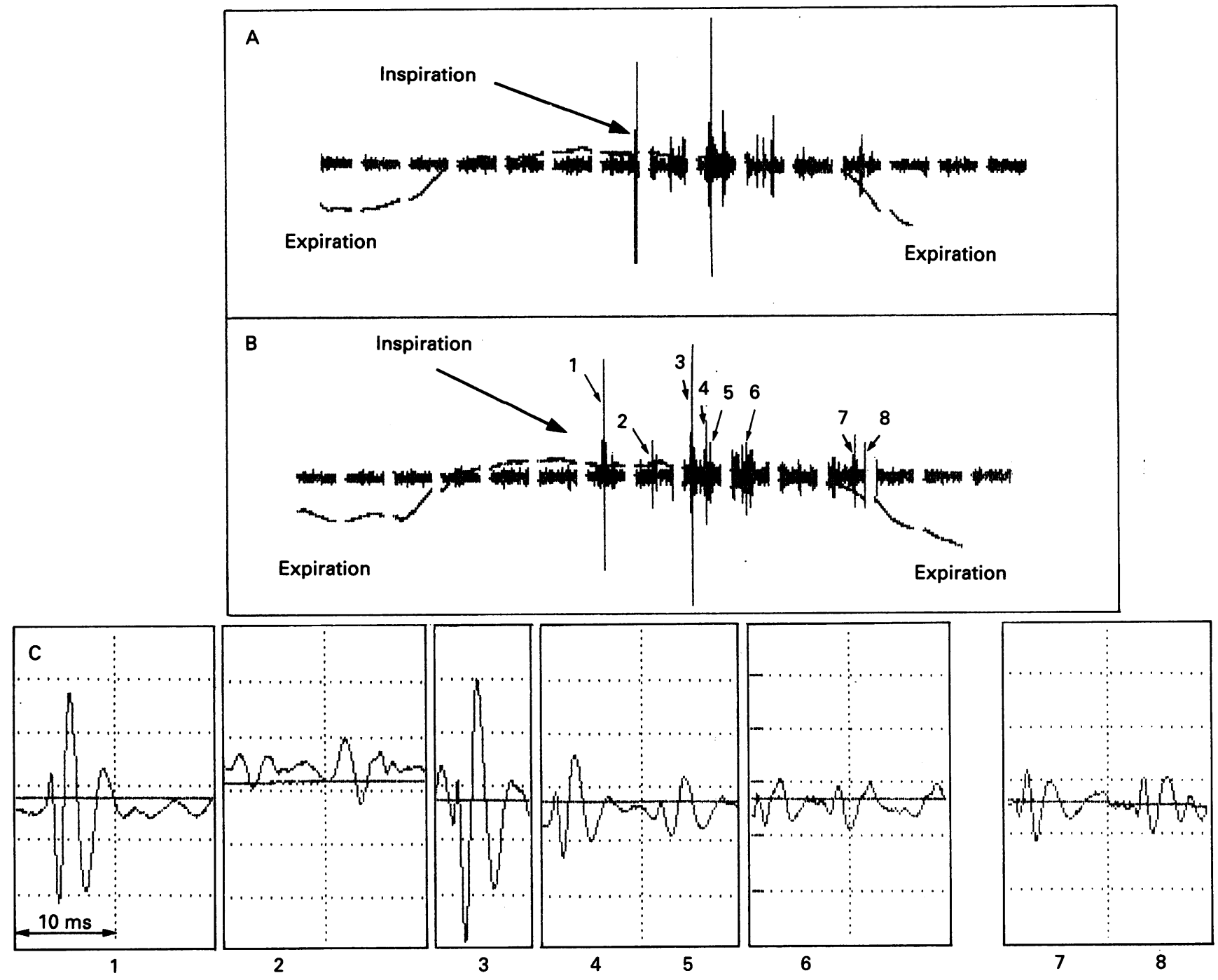

Figure 7 Two respiratory cycles $(A)$ and (B) showing repetitive mid to late fine inspiratory crackles in an asbestos worker. Crackles are fine as shown by the detailed display $(C)$ (see text).

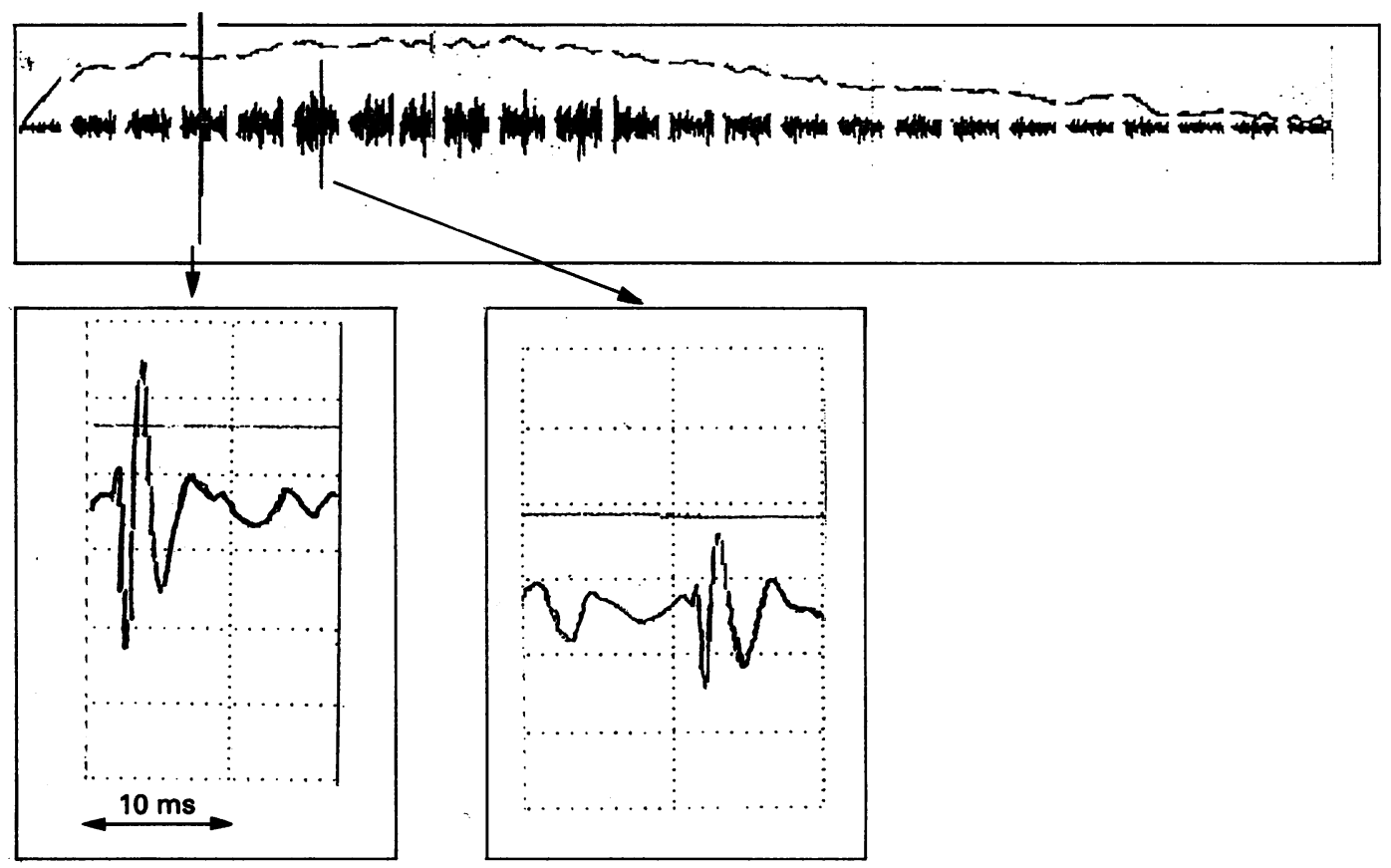

Figure 8 Early fine inspiratory crackles in a 33 year old healthy smoker. Crackles were repetitive on successive respiratory cycles. 
alveolar thickening and peribronchiolar fibrosis may be sufficient to give rise to crackles but not to any radiographic abnormality. In this study the crackles detected in subjects with radiographic opacities of $\leqslant 1 / 0$ were similar in character to those found in all the subjects with radiographic evidence of asbestosis, consistent with the crackles being evidence of early asbestosis.

Interexaminer agreement on the presence or absence of definitive signs of asbestosis on the chest radiograph and HRCT was more than $90 \%$ whereas the agreement on the presence or absence of crackles on auscultation was relatively poor $(71 \%)$. We have previously found good agreement between examiners on the degree of lung fibrosis in asbestos workers on the chest radiograph and HRCT ${ }^{22}$ and considerable disagreement on the presence, nature (coarse and fine), and timing of respiratory cycle of lung crackles by auscultation. ${ }^{23}$ We have not examined the interexaminer agreement on the presence of crackles on TEW but it has been investigated previously and shown to be high. ${ }^{16}$

It could be argued that a chest radiograph classified as $1 / 0$ is abnormal. Most investigators, however, consider the chest radiograph definitely abnormal only if the profusion of opacities is $1 / 1$ or more. Moreover the interobserver disagreement on a score of $1 / 0$ is high. In a previous study we reported that the agreement between observers on the degree of radiographic opacities on the ILO scale was good for the major categories of the ILO scale $(0,1,2,3) .{ }^{22}$ Disagreement on the minor categories was, however, considerable. In particular the interexaminer disagreement on the category $1 / 0$ in lung zones of 60 patients ( 360 zones) was considerable. This score was reported on 15 lung zones by the first examiner and on 18 lung zones by the second, but the two examiners agreed on a score of $1 / 0$ on only five zones.

Crackles in the control group who were current or previous smokers differed from those seen in asbestosis (figs 7 and 8 ). Crackles were fine and early inspiratory. These results are similar to those in a previous study which reported that in 56 healthy nurses fine mid inspiratory crackles were audible by auscultation in 35 and detectable by TEW in 53. ${ }^{24}$ The cause of these crackles may be forceful opening during inspiration of physiologically collapsed, or partly collapsed small airways, or both. There is no difficulty in distinguishing these "normal" crackles from those suggesting interstitial fibrosis on TEW.

HRCT was not performed in the control group. Pulmonary opacities found in normal lungs, however, have previously been described ${ }^{25} 26$ and the types of opacities we selected to make the HRCT diagnosis of fibrosis (discrete lines, ground glass shadows, and reticulonodular opacities) are not found in healthy lungs.

This study shows that lung crackles in asbestos workers are detected by TEW more frequently than by auscultation. Signs of early asbestosis not apparent on plain radiography are detected by TEW and HRCT with similar frequency. TEW is probably less specific but has the advantages of being simple, inexpensive, and without hazard and may therefore be preferable to HRCT for screening groups of workers for early signs of asbestosis.

1 Becklake MR Asbestos-related disease of the lung and other organs: their epidemiological implications for clinical practice. Am Rev Respir Dis 1976;114:187-227.

2 Katz D, Kreel L. Computed tomography in pulmonary asbestosis. Clin Radiol 1979;30:207-13.

3 Staples CA, Gamsu G, Ray CS, Webb WR. High resolution computed tomography and lung function in asbestos workers with normal chest radiograph. $A m$ Rev Respir Dis 1989;139:1502-8.

4 Lozewicz S, Renznek RH, Herdman M, Dacie JE, McLean A, Davies RJ. Role of computed tomography in evaluating asbestos related lung disease. $\mathrm{Br} \mathcal{F}$ Ind Med 1989;46:777-81.

5 Epler GR, Gaensler EA, Carrington CB. Crackles (rales) in interstitial pulmonary disease. Chest 1978;73:333-9.

6 Smither WJ. Secular changes in asbestosis in an asbestos factory. Biological effects of asbestosis. Ann NY Acad Sci 1965;132:166-81.

7 Kleinfield M, Messite J, Kooyman O, Sarfaty J. Effect of asbestos dust inhalation on lung function. Arch Environ Health 1966;12:741-51.

8 Smyllie HC, Blendis LM, Armitage P. Observer disagreement in physical signs of the respiratory system. Lancet 1965;ii:477.

9 Murphy RLH, Sorensen K. Chest auscultation in the diagnosis of pulmonary asbestosis. $f$ Occup Med 1973;15:272-6.

10 Shirai F, Kudoh S, Shibuya A, Sada K, Mikami R. Crackles in asbestos workers: auscultation and lung sound analysis. $\operatorname{Br} \mathcal{F}$ Dis Chest 1981;75:386-96.

11 Murphy RLH, Gaensler EA, Holford SK, DelBono EA, Epler G. Crackles in early detection of asbestosis. Am Rev Respir Dis 1984;129:375-9.

12 International Labour Office. U/C international classification of radiographs of pneumoconiosis in occupational safety and of radiographs of pneumoconiosis in occupational safety and

13 Strickland B, Brennan J, Denison DM. Computed tomography in diffuse lung disease: improving the image. Clin Radiol 1986;3:335-8.

14 Strickland B, Strickland NH. The value of high definition, narrow section computed tomography in fibrosing alveolitis. Clin Radiol 1988;39:589-94.

15 Al Jarad N, Strickland B, Pearsom MC, Rubens MB, Rudd RM. High resolution computed tomographic assessment of asbestosis and cryptogenic fibrosing alveolitis: comparative study. Thorax 1992;47:645-50.

16 Murphy RLH, DelBono EA, Davidson F. Validation of an automatic crackle(rales) counter. Am Rev Respir Dis 1989;140:1017-20.

17 Loudon R, Murphy JR. RLH. State of the art lung sounds. Am Rev Respir Dis 1984;130:663-73.

18 Cotes JE. Lung function: assessment and application in medicine. 4th edn. Oxford: Blackwell, 1978:281-7.

19 Altman DG. McNemar's test. In: Practical Statistics for medical research. 1st edn. London: Chapman and Hall 1991:258-9.

20 Wallace WFM, Langlands JHM. Insulation workers in Belfast. 1. Comparison of a random sample with a control population. $\mathrm{Br} \mathcal{F}$ Ind Med 1971;28:211.

21 Leatheart GL. Pulmonary function tests in asbestos workers. Trans Soc Occup Med 1968;18:49-60.

22 Al Jarad N, Wilkinson P, Pearson MC, Rudd RM. A new high resolution computed tomography scoring system for pulmonary fibrosis, pleural disease and emphysema in patients with asbestos related disease. Br $\mathcal{F}$ Ind Med in patients with

23 Al Jarad N, Bothamley G, Lock SH, Logan-Sinclair R, Rudd RM. Assessment of lung crackles by computerised lung sound analysis: a comparison with auscultation. Thorax 1991;46:774 (abstract).

24 Workum P, Holford SK, Del Bono EA, Murphy RLH. The prevelance and character of crackles (rales) in young women without significant lung disease. Am Rev young women without sign

25 Muller NL, Miller RR. Computed tomography of chronic diffuse infiltrated lung disease, part I. Am Rev Respir Dis 1990;142:1206-15.

26 Webb WR, Muller NL, Naidich DP. Normal lung anatomy. In: High resolution $C T$ of the lung. 1st edn. New York: Raven Press, 1992:14-23. 